\title{
Relações entre o Setor Público e o Privado no Financiamento da Educação: provimento do cargo de diretor escolar em redes públicas de ensino
}

\author{
Regina Tereza Cestari de Oliveira \\ Universidade Católica Dom Bosco (UCDB), Campo Grande/MS - Brasil
}

\section{Resumo}

Este artigo aborda as relações entre o setor público e o privado no financiamento da educação. Para tanto, se baseia em resultados de pesquisa que mostram a contratação de uma mesma instituição privada para execução do processo seletivo, incluindo o mecanismo de certificação ocupacional como forma de provimento do cargo de diretor escolar, na Rede Municipal de Ensino de Campo Grande, capital do estado de Mato Grosso do Sul, no período de 2001 a 2004, e na Rede Estadual de Ensino de Mato Grosso do Sul, de 2007 a 2010 . A investigação baseia-se na análise de fontes documentais e os resultados evidenciam que a Fundação Luis Eduardo Magalhães, do estado da Bahia, foi escolhida para implantar a certificação ocupacional em ambas as redes de ensino, comprometendo o processo de construção da gestão democrática da educação, com recebimento de recursos públicos.

Palavras-chave: Parceria Público-Privada. Provimento do Cargo de Diretor Escolar. Financiamento da Educação.

\section{Relations Between Public and Private Sector in Education Funding:} filling of the position of school principal in educational public

\section{systems}

\begin{abstract}
This article discusses the relations between public and private sector in education funding. It is based on research results showing the hiring of the same private institution to run the selection process, including the occupational certification mechanism as a way of filling the position of school principal in the Municipal Education System of Campo Grande, state capital of Mato Grosso do Sul, Brazil from 2001 to 2004, and the State Education System of Mato Grosso do Sul from 2007 to 2010 . The research is based on analysis of documents and the results show that the Luis Eduardo Magalhães Foundation, from the state of Bahia, was chosen to implement the occupational certification in both systems, compromising the process of building the democratic management of education with receipt of public funds.
\end{abstract}

Keywords: Public-Private Partnership. Filling of the Position of School Director. Education Funding. 
Relações entre o Setor Público e o Privado no Financiamento da Educação

\section{Introdução}

Este artigo aborda as relações entre o setor público e o setor privado no financiamento da educação. Para tanto, apresenta resultados de duas pesquisas ${ }^{1}$ que mostram o destino de recursos públicos a uma mesma instituição privada, em períodos e governos distintos, para execução do processo seletivo, incluindo o mecanismo de certificação ocupacional, como forma de provimento do cargo de diretor escolar. A primeira refere-se à pesquisa ${ }^{2}$ realizada na Rede Municipal de Ensino de Campo Grande, Mato Grosso do Sul (MS), no âmbito da parceria efetivada entre o governo municipal de Campo Grande, capital do estado de Mato Grosso do Sul, e o Instituto Ayrton Senna (IAS), na gestão do prefeito André Puccinelli (20012004), do Partido do Movimento Democrático Brasileiro (PMDB). A segunda refere-se à pesquisa ${ }^{3}$ na Rede Estadual de Ensino de Mato Grosso do Sul, no âmbito do Plano de Ações Articuladas (PAR), na gestão do governador André Puccinelli (2007-2010), do mesmo partido.

Apresentam-se, a seguir, os resultados da pesquisa correspondentes ao primeiro período, ou seja, de 2001 a 2004, referentes à Rede Municipal de Ensino de Campo Grande (MS).

\section{O provimento do cargo de diretor escolar na Rede Municipal de Ensino de Campo Grande (MS) e o financiamento da educação}

No atual contexto do capitalismo, marcado por intenso processo de globalização econômica e financeira e de redefinição do papel do Estado, a relação entre o público e o privado ganha novos contornos e se materializa de diversas formas (PERONI; OLIVEIRA; FERNANDES, 2009).

No caso brasileiro, o Plano Diretor da Reforma do Aparelho do Estado (PDRAE), documento elaborado pelo então Ministério da Administração e da Reforma do Estado (MARE), aprovado em 21 de setembro de 1995, no Governo de Fernando Henrique Cardoso (1995-1998) (BRASIL, 1995), definiu as estratégias de privatização, descentralização e publicização (público não estatal). O PDRAE expressa a nova forma de relação entre o público e o privado no País, no campo das políticas sociais, de forma geral, e da política educacional, particularmente, e indica, como uma das formas dessa relação, as parcerias entre o terceiro setor e os sistemas públicos de ensino.

No PDRAE, as políticas sociais são consideradas serviços não exclusivos do Estado e, portanto, de propriedade pública não estatal ou privada, por exemplo, os serviços de educação, saúde, cultura e pesquisa científica (BRASIL, 1995). Nesse sentido, remete-se à sociedade civil, por meio do terceiro setor, a responsabilidade pela implementação de políticas sociais (PERONI, 2008), "[...] em nome da autonomia, da solidariedade, do altruísmo, e do

1 Os resultados correspondem a duas pesquisas realizadas em períodos específicos. A primeira, no período de 2001 a 2004, na Rede Municipal de Ensino de Campo Grande, MS. A segunda, no período de 2007 a 2010, na Rede Estadual de Ensino de Mato Grosso do Sul.

2 A pesquisa, denominada "Parcerias público e privado na educação: implicações para a oferta e gestão educacional", contou com o apoio da Fundação de Apoio ao Desenvolvimento do Ensino, Ciência e Tecnologia do Estado de Mato Grosso do Sul (FUNDECT).

3 A pesquisa, denominada "Planejamento da Educação em municípios sul-mato-grossenses: implicações para a gestão democrática e o direito à educação", contou com o apoio da Fundação de Apoio ao Desenvolvimento do Ensino, Ciência e Tecnologia do Estado de Mato Grosso do Sul (FUNDECT). 
interesse geral, sendo que sua propagação é induzida com subsídio público" (PERONI; OLIVEIRA; FERNANDES, 2009, p. 768).

A ideia de eficiência, presente no PDRAE, ganhou status constitucional com o Art. 37 da Emenda Constitucional n ${ }^{\circ} 19$ de $1998^{4}$, como analisam Adrião e Bezerra (2013), e permitiu "[...] a flexibilização das relações entre a iniciativa privada e o poder público, a partir da inserção de práticas gerenciais advindas de modelos privatistas, considerados, nessa perspectiva, mais eficientes e ágeis". Além disso, a flexibilização desses acordos "[...] foi ampliada a partir do estabelecimento de parcerias, firmados por um novo instrumento jurídico, dado pela introdução do contrato de gestão no âmbito da Administração Pública" (ADRIÃO; BEZERRA, 2013, p. 264).

Ao assumirem, progressivamente, a oferta do ensino fundamental em função do cumprimento das normas legais definidas na Constituição Federal de 1988 (BRASIL, 1988) e na Lei de Diretrizes e Bases da Educação Nacional (LDBEN) (BRASIL, 1996) e responder às demandas por acesso, permanência e qualidade, vários municípios buscaram realizar parcerias com instituições que integram o chamado terceiro setor (OLIVEIRA, 2012), ou seja, organizações não-governamentais (ONGs), instituições filantrópicas e comunitárias e outras associações similares. Ressalta-se que esses organismos, "[...] criados com o objetivo de prover serviços sociais na área de saúde, educação, proteção contra o crime, transporte público, enfim, de alívio à pobreza, têm em comum o fato de serem não-lucrativos e fazerem parte da sociedade civil" (PERONI; OLIVEIRA; FERNANDES, 2009, p. 768).

Nesse contexto, o governo do Município de Campo Grande estabeleceu parceria ${ }^{5} \mathrm{com}$ o Instituto Ayrton Senna (IAS), para o desenvolvimento do Programa Escola Campeã, mediante a assinatura do Termo de parceria em 24 de janeiro de 2001, no segundo mandato do prefeito André Puccinelli (2001-2004), do Partido do Movimento Democrático Brasileiro (PMDB).

O mencionado Termo assinala que a adesão à parceria foi iniciativa da Prefeitura Municipal que "[...] tendo tomado conhecimento do Programa e dos princípios que o norteiam, e visando estabelecer uma estratégia permanente que viabilize uma educação de qualidade para todos manifestou seu interesse em participar do Programa como parceiro empreendedor" (CAMPO GRANDE, 2001).

Foram acrescentados ao Termo de parceria três termos aditivos. O primeiro Termo Aditivo, celebrado em 02 de setembro de 2002, vigorou até o dia 31 de dezembro de 2002. O segundo Termo Aditivo, celebrado em primeiro de janeiro de 2003, vigorou até o dia 31 dezembro de 2003, e o terceiro Termo Aditivo, celebrado em $1^{\circ}$ de janeiro de 2004, vigorou até o dia 30 de dezembro de 2004 (OLIVEIRA, 2012).

Para a realização do Programa, a Prefeitura comprometeu-se, entre outros, a "[...] desenvolver uma política prioritária em educação centrada no ensino fundamental e na

$4 \quad$ Art. 37 - "A administração pública direta e indireta de qualquer dos Poderes da União, dos Estados, do Distrito Federal e dos Municípios obedecerá aos princípios de legalidade, impessoalidade, moralidade, publicidade e eficiência [...]" (BRASIL, 1988).

5 Aqui, o termo parceria designa, genericamente, os acordos formalmente firmados pelas esferas governamentais com setores da iniciativa privada. Considerando a natureza do objeto investigado, optou-se por distingui-los em função da natureza jurídico-administrativa das partes envolvidas, em que o público é identificado por ser mantido e ou gerido pelo poder governamental ou por entidades de direito público e, privado, é definido pela gerência e propriedade de pessoas físicas ou jurídicas de direito privado (DOURADO; BUENO, 1999). 
promoção da autonomia e integração das escolas da rede pública municipal" e "[...] a promover e ou dar início à reforma legislativa necessária para a autonomia das escolas que compõem a rede pública municipal" (CAMPO GRANDE, 2001).

É importante lembrar, como acentua Adrião (2006), que a autonomia concedida à escola pública deve ser considerada como autonomia relativa. Em suas palavras,

\section{[...] É certo, também, que a 'autonomia' da escola pública é sempre limitada principalmente no que se refere aos insumos, uma vez que depende das políticas governamentais adotadas. De maneira análoga a 'autonomia pedagógica' das escolas públicas, ou das particulares, é limitada pelo conjunto de normas legais e institucionais que as organizam. Portanto, quando se fala em autonomia para a escola, cabe adjetivá- la: autonomia relativa (ADRIÃO, 2006, p. 71).}

Verifica-se que, no período de vigência da parceria, o Decreto n. 8.508, de 7 de agosto de 2002, dispôs sobre o provimento do cargo em comissão de Direção escolar, e instituiu o processo seletivo na Rede Municipal de Ensino de Campo Grande (MS) (CAMPO GRANDE, 2002a).

A Resolução SEMED n 50, de 7 de agosto de 2002 (CAMPO GRANDE, 2002b), por sua vez, instituiu o processo seletivo para dirigentes das escolas municipais, "[...] com a finalidade de melhorar a gestão das unidades escolares, mediante a indicação de servidor que evidencie conhecimentos e habilidades próprias para o desempenho do cargo" (Art. $1^{\circ}$ ), ao mesmo tempo que estabeleceu os requisitos básicos necessários para participação no processo seletivo, ou seja: ser servidor estável detentor de cargo integrante do Quadro Permanente do Pessoal do Magistério da Prefeitura Municipal de Campo Grande; possuir habilitação com curso de Graduação, licenciatura plena; possuir experiência de, no mínimo, três anos de efetivo exercício em função de magistério, na Rede Municipal de Ensino (Art. $3^{\circ}$ ).

Salienta-se que a mencionada Resolução não menciona para inscrição no processo seletivo a área do curso de Graduação, assim não define como exigência, por exemplo, o curso de Pedagogia, mas licenciatura plena em geral (OLIVEIRA, 2013).

A mesma Resolução estabeleceu etapas para esse processo: etapa I - Seleção Interna de Servidores, para escolha de um participante no processo seletivo no âmbito da escola, da Secretaria Municipal de Educação (SEMED) e da entidade classista; etapa II - Curso de Capacitação em Gestão Escolar; etapa III - Certificação Ocupacional, mediante a realização de provas objetivas e descritivas de caráter eliminatório, a fim de avaliar conhecimentos específicos, comunicação e expressão da Língua Portuguesa e questões práticas de gestão escolar (Art. $4^{\circ}$ ). A Resolução determinou, ainda, em seu Art. 10, que "[...] a relação de servidores aprovados no Exame de Certificação integrará o Banco de Candidatos à Direção Escolar, para posterior indicação ao provimento de cargo pelo Poder Executivo" (CAMPO GRANDE, 2002b).

Como se verifica, o governo do Município de Campo Grande optou pela introdução do mecanismo de certificação ocupacional, embora, em última instância, a direção escolar, no período, continuou sendo de livre nomeação e exoneração do Poder Executivo.

Salienta-se que no segundo Termo aditivo, conforme a cláusula terceira, alínea n, o município se comprometeu em "[...] viabilizar a seleção meritória dos diretores da rede pública de ensino, promovendo uma prova de competência técnica para a avaliação dos candidatos" (CAMPO GRANDE, 2003a). 
Para a execução do processo seletivo, incluindo o curso de capacitação, a elaboração e aplicação das provas, tendo em vista a certificação ocupacional, foi escolhida a Fundação Luis Eduardo Magalhães (FLEM) ${ }^{6}$, do estado da Bahia, parceira do IAS, no desenvolvimento do Programa Escola Campeã (CAMPO GRANDE, 2003b). Em proposta técnica encaminhada à Secretaria Municipal de Educação de Campo Grande, a FLEM afirma,

De caráter inovador, a Certificação Ocupacional consiste em um sistema que prima por estabelecer padrões de mérito e competência, constituindo-se num processo desenvolvido para atestar que os profissionais possuem as competências básicas necessárias para o desempenho das atividades relacionadas à sua ocupação.

[...] A Certificação Ocupacional traz como benefícios para os profissionais que participam desse processo a clara definição do que é esperado deles, competências que devem desenvolver ou aperfeiçoar para o exercício eficaz de suas funções, bem como o reconhecimento público de suas competências. Esse processo possibilita, ainda, o estímulo à educação continuada, a fim de garantir a atualização das competências estratégicas e sistemas meritocráticos de reconhecimento pelo desempenho (FUNDAÇÃO LUIS EDUARDO MAGALHÃES, 2004, p.1).

O referido exame, segundo a Fundação Luís Eduardo Magalhães (2004, p. 3), compreende a aplicação de Teste de Conhecimentos Específicos (T1), Teste de Comunicação e Expressão da Língua Portuguesa (T2) e Teste de Questões Práticas (T3).

O terceiro Termo aditivo, ao alterar, mais uma vez, a cláusula das responsabilidades da Prefeitura Municipal de Campo Grande, manteve o compromisso em relação à seleção de diretores escolares. O documento explicita que, para a total realização do Programa, a Prefeitura se compromete a: "Viabilizar a seleção meritória de todos os diretores da rede pública de ensino, promovendo uma prova de competência técnica para a avaliação e promoção/contratação dos candidatos" (CAMPO GRANDE, 2004a).

Assim, em consonância com as responsabilidades assumidas no âmbito da parceria, a Secretaria Municipal de Educação de Campo Grande, em documento denominado "Rede Municipal de Ensino: política educacional" definiu como "condição essencial para se alcançar uma escola eficaz, o fortalecimento da gestão", tanto no órgão central como nas unidades escolares, com o argumento de que o "[...] reordenamento da gestão da educação faz-se necessário na medida em que as práticas de gestão devem contribuir para melhoria dos indicadores de qualidade do ensino". Para tanto, destaca a necessidade da implementação de algumas diretrizes, entre elas, a "[...] seleção de dirigentes ressaltando a competência técnica, mérito, liderança, relacionamento interpessoal e preocupação com os resultados da escola" (CAMPO GRANDE, 2004b, p. 21, grifos do autor).

Como se verifica, o documento relaciona a necessidade de mudanças nas práticas de gestão, com a obtenção dos resultados educacionais com vistas à escola eficaz, entre elas, a seleção de "dirigentes" escolares, segundo critérios meritocráticos. Nestes, utilizando as

6 O Estatuto da Fundação à época, capítulo I, Art.1², esclarece: "[...] Fundação com personalidade jurídica de direito privado, declarada de utilidade pública, sem fins lucrativos, cuja instituição foi autorizada pela Lei $n^{\circ}$. 7.349, de 12 de julho de 1998, alterada pela Lei $n^{\circ}$. 8.726, de 20 de agosto de 2003, com sede e foro na Cidade do Salvador, capital do Estado da Bahia, Brasil, à $3^{a}$ Avenida, 310, Centro Administrativo da Bahia - CAB, jurisdição em todo o Estado da Bahia e atuação em âmbito nacional e internacional, prazo indeterminado de duração, também denominada FLEM". Disponível em: <http://www.flem.org.br/paginas/fundacao/fundacao. jsp>. Acesso em: 2 jul. 2009. 
palavras de Adrião (2006, p. 62), "[...] a ênfase numa necessária reestruturação institucional das unidades escolares e dos órgãos gestores da educação pública assume a forma do aumento da 'responsabilização' das próprias escolas frente ao fracasso do sistema educacional público".

Acrescenta-se que, entre as atribuições do diretor escolar para permanência no cargo, elencadas no artigo 11 da Resolução SEMED n 50 , de 7 de agosto de 2002, consta que o servidor nomeado para o cargo de Diretor deverá "I- revalidar, a cada 3 (três) anos, a certificação ocupacional" (CAMPO GRANDE, 2002b). Registra-se que, em 2006, ocorreu a primeira revalidação para os candidatos aprovados e nomeados em 2002 (BOLSON, 2011, p. 109).

Sobre o processo seletivo, Bolson (2011, p. 70-71) assinala que, por um lado, a posição da Secretaria Municipal de Educação era desfavorável à realização de eleição como forma de provimento do cargo de diretor escolar, defendida, por sua vez, pelo Sindicato, por outro, os diretores escolares que já ocupavam o cargo não levantaram a bandeira de eleição direta. Em suas palavras, "Acabaram submetendo-se às provas, uma vez que o interesse era a manutenção da situação em que estavam, pois parece que era mais favorável. Os professores, supervisores e orientadores que foram selecionados para o processo, poderiam ser indicados pelo mérito da aprovação".

Diante disso, a autora conclui,

O processo de seleção para a função de diretor de escola, a certificação ocupacional adotada pelo município de Campo Grande/MS, tornou-se um critério para o acesso ao cargo de diretor de escola, modificou a rotina das escolas, na medida em que introduziu técnicas da gestão gerencial como forma de melhorar a gestão, focando na eficácia e nos resultados. Nesse processo, os diretores buscaram formação nos conteúdos exigidos pela Fundação Luís Eduardo Magalhães como forma de garantir aprovação nas avaliações para a permanência no cargo (BOLSON, 2011, p. 113).

A opção da Secretaria Municipal de Educação por essa forma de provimento do cargo de diretor escolar indica o modelo de gestão que se propõe para as escolas da Rede Municipal de Ensino de Campo Grande (MS), sustentada nos padrões de eficiência e eficácia ${ }^{7}$ do ensino, conceitos que orientam o Programa Escola Campeã e que se fundamentam na concepção de gestão gerencial.

É importante frisar o entendimento de que a eleição de diretores escolares não garante a gestão democrática, no entanto, pode se constituir em instrumento de sua construção, uma vez que, utilizando as palavras de Dourado (2001, p. 79):

[...] é um processo de aprendizado e de luta política que não se circunscreve aos limites da prática educativa, mas vislumbra, nas especificidades dessa prática social e de sua relativa autonomia, a possibilidade de criação de canais de efetiva participação e de aprendizado do 'jogo' democrático e, consequentemente, do repensar das estruturas de poder autoritário que permeiam as relações sociais e, no seio dessas, as práticas educativas. Deste modo, entende-se que a gestão democrática não só requer mais do que simples mudanças nas estruturas organizacionais, mas também exige mudanças

Segundo essa perspectiva, concordando com os termos de Adrião e Garcia (2008, p. 782): "Por eficácia entendese o resultado obtido pela ação escolar ao alcançar os objetivos educacionais previamente definidos. Já a eficiência refere-se ao atendimento desses objetivos com maior economia de esforços e recursos possíveis. A produtividade da escola estaria, então, relacionada a existência de processos mais eficazes e mais eficientes". 
Relações entre o Setor Público e o Privado no Financiamento da Educação

de paradigmas que fundamentem a construção de uma proposta educacional e o desenvolvimento de um tipo de gestão diferente para além dos padrões autoritários vigentes impostos pelas organizações burocráticas.

No âmbito do processo seletivo, o material utilizado no "Curso de Capacitação em Gestão Escolar" para candidatos ao exame, tendo em vista a certificação ocupacional, foi elaborado pela referida Fundação. Para o Curso, a Fundação utilizou dois manuais, ou seja, "Manual de Procedimento e Rotinas", e "Gerenciando a Escola Eficaz - conceitos e instrumentos". Os manuais, segundo Bolson (2011), são os mesmos utilizados pelo Instituto, no desenvolvimento do Programa Escola Campeã, que orientou os diretores e diretoresadjuntos no início da parceria. Em outros termos,

Os manuais utilizados para o curso de capacitação elaborado pela Fundação Luís Eduardo Magalhães orientam o diretor em como deve organizar a escola para que seja eficaz, já que é o responsável pelo sucesso ou pelo fracasso das ações desenvolvidas pela escola. Segundo o manual, '[...] se os alunos não aprendem, o problema está na escola: na forma como ela funciona e na forma como ela se organiza'. Ainda segundo o manual, as pessoas sabem identificar as escolas boas, e o diretor é que faz essa escola ser boa. Assim, '[...] Para o diretor, o grande desafio é saber como transformar a sua escola numa boa escola'. No Manual da FLEM, as propostas implantadas para a gestão da escola estão apoiadas em metodologias para fortalecer a capacidade de liderança e gerenciamento do diretor (BOLSON, 2011, p. 73- 74, grifos da autora).

Quanto aos recursos financeiros, os dados levantados na pesquisa não possibilitaram identificar, exatamente, as despesas referentes à parceria com o IAS, porém, mostraram o pagamento à Fundação Luís Eduardo Magalhães, parceira do Instituto na execução do Programa para implantação do processo seletivo, como já mencionado, tendo em vista a certificação ocupacional.

Por exemplo, o Contrato $n^{\circ} 99$, de 22 de julho de 2003, especificou o valor de $R \$$ 135.038, 56 (Cento e trinta e cinco mil, trinta e oito reais e cinquenta e seis centavos) para pagamento pela Prefeitura Municipal à Fundação Luís Eduardo Magalhães (CAMPO GRANDE, 2003b).

Em 2004, a Prefeitura Municipal de Campo Grande estabeleceu nova parceria com a Fundação Luís Eduardo Magalhães (FLEM) para a realização do $3^{\circ}$ exame de Certificação Ocupacional, com a justificativa de que,

Necessário se faz, portanto, para 2004, que se estabeleça nova parceria com a Fundação Luís Eduardo Magalhães, a fim de que realizemos o $3^{\circ}$ Processo Seletivo Interno da REME - Certificação Ocupacional. Justifica-se, diante do exposto, a opção pela prestadora de serviços acima referida, já que atende às expectativas desta Secretaria, e também pelo fato de o preço apresentado estar compatível com o praticado pelo mercado (CAMPO GRANDE, 2004a, p. 1).

O argumento apresentado sobre os gastos públicos para o setor privado remete à análise de Adrião et al. (2009, p. 803-804), que afirmam:

[...] apresenta-se como justificativa para a opção de políticas governamentais que se apoiam na esfera privada, subvencionando-a, em troca da transferência da lógica de organização privada para o setor público, ao invés de reverter esses recursos públicos para a melhoria e/ou consolidação do aparato governamental necessário à manutenção e ao desenvolvimento do ensino. 
O contrato com a FLEM para o $3^{\circ}$ exame de Certificação Ocupacional, $n^{\circ} 174$, de 7 de julho de 2004, no valor de $\mathrm{R} \$ 200.000,00$ (duzentos mil), foi pago em quatro parcelas, sendo estipulado o mesmo valor por candidato correspondente ao contrato $n^{\circ} 99$, de 22 de julho de 2003. Infere-se que houve maior número de participantes, uma vez que o valor, por candidato, foi o mesmo, enquanto o valor do contrato foi maior (BOLSON, 2011, p. 87).

No período da parceria com o IAS foram realizados, portanto, três exames de certificação ocupacional na Rede Municipal de Ensino de Campo Grande, com a participação de "682 candidatos entre diretores, diretores adjuntos e professores selecionados" (BOLSON, 2011, p. 87).

Os documentos analisados mostraram que a parceria com o Instituto Ayrton Senna não teve continuidade no governo seguinte, ou seja, na gestão do prefeito Nelson Trad Filho (2005-2008), também, à época, do PMDB, porém, esse governo manteve o processo seletivo para provimento do cargo de diretor escolar, compreendendo a certificação ocupacional. E mais, incluiu a quarta etapa nesse processo, ou seja, o "Acompanhamento Sistemático" para diretores escolares. Assim, as práticas gerenciais introduzidas no âmbito da parceria foram mantidas e/ou intensificadas, com ênfase nos resultados, na lógica da competência e na responsabilização do diretor escolar (DANTAS, 2011), indicando que os princípios da gestão gerencial orientam o planejamento da Rede Municipal de Ensino do município.

Feitas essas considerações, pode-se afirmar que, apesar de a Constituição Federal de 1988 estabelecer a gestão democrática como um dos princípios do ensino, reafirmado pela LDBEN em 1996, a forma de provimento do cargo de diretor na Rede Municipal de Ensino de Campo Grande continuou sendo por indicação política. Assim, os governos mencionados do município não levaram em consideração a eleição para diretores escolares como instrumento de gestão democrática. Com a introdução do mecanismo de certificação ocupacional no processo seletivo, a indicação continuou sendo, em última instância, prerrogativa do chefe do Poder Executivo. Embora a eleição não se caracterize como único instrumento de gestão democrática, como já assinalado, possibilita maior participação dos sujeitos da escola nas decisões e, portanto, pode contribuir para o avanço de práticas democráticas.

$\mathrm{Na}$ seção seguinte serão apresentados resultados da pesquisa correspondentes ao segundo período indicado, ou seja, de 2007 a 2010, na Rede Estadual de Ensino de Mato Grosso do Sul'.

\section{O provimento do cargo de diretor escolar na Rede Estadual de Ensino de Mato Grosso do Sul e o financiamento da educação}

Em 2006, André Puccinelli foi eleito governador do estado de Mato Grosso do Sul, pelo PMDB. Ao assumir o governo nomeou como Secretária de Estado de Educação Maria Nilene Badeca da Costa (2007-2014), que havia ocupado esse cargo na Secretaria Municipal de

8 O Estado de Mato Grosso do Sul foi criado a partir da divisão do Estado de Mato Grosso, no governo do presidente Ernesto Geisel (1974-1979), por meio da Lei Complementar n 31, de 11 de outubro de 1977. A instalação do Governo Estadual de Mato Grosso do Sul ocorreu em primeiro de janeiro de 1979. Situa-se na Região Centro-Oeste e faz fronteira, a sudoeste, com as Repúblicas do Paraguai e da Bolívia; a Sudeste, com os Estados de Minas Gerais e São Paulo; ao Sul, com o Paraná; e, ao norte, com Mato Grosso e Goiás. Possui 79 municípios distribuídos em área de $357.545,534, \mathrm{Km} 2$, com população, conforme censo de 2010 , de 2.449.014 habitantes, estimada em 2015 em 2.651.235 habitantes. Disponível em: <http://ww.ibge.gov.br/estadosat/perfil.php?lang=\&sigla=MS>. Acesso em: 7 jul. 2016. 
Educação (SEMED) durante os dois mandatos em que ele havia sido prefeito de Campo Grande (1997-2000 e 2001-2004). Como base política/administrativa da Secretaria para dar continuidade às diretrizes educacionais na Rede Estadual de Ensino de Mato Grosso do Sul, o governo compôs com o mesmo corpo de técnicos que havia integrado a equipe no período de 1997 a 2004 (BIGARELLA, 2015).

Bigarella (2015) assinala que, com base na concepção denominada "Educação para o Sucesso", conforme o texto da Mensagem à Assembleia Legislativa (2009), o governo propôs "[...] apoiar os diretores escolares no desenvolvimento de um modelo de gestão focado na autonomia da escola, como estratégia de melhorar os resultados da Educação Sul-matogrossense" (MATO GROSSO DO SUL, 2009, p. 138).

Nesse sentido, a primeira ação a destacar refere-se ao encaminhamento pelo Executivo de projeto de lei à Assembleia Legislativa de Mato Grosso do Sul, com alterações no processo de provimento do cargo de diretores escolares, regulamentado pela Lei $n^{\circ} 3.244$, de 6 de junho de 2006, aprovada no governo José Orcírio dos Santos (1999-2006), do Partido dos Trabalhadores (PT), por meio de eleição direta pela comunidade escolar. Após tramitação do projeto na Assembleia Legislativa do Estado de Mato Grosso do Sul, foi aprovada a Lei $n^{\circ}$ 3.479 , de 20 de dezembro de 2007, que definiu o processo "eletivo" ao cargo de "dirigentes" escolares em três etapas, conforme Art. 10: curso de capacitação em gestão escolar; avaliação de competências básicas de dirigentes escolares; e eleição (MATO GROSSO DO SUL, 2007).

Como analisa Fernandes (2010, p. 7),

Para a gestão da educação básica, a 'Educação para o Sucesso' alterou significativamente o processo de eleição para diretores. Inicialmente, o atual governador considerou importante rever o processo de eleição para diretor que se daria em 2008 e cogitou até a eliminação do pleito eleitoral. Com a reação dos trabalhadores em educação organizados na Federação dos Trabalhadores em Educação de Mato Grosso do Sul (FETMS), foi necessário rever posições.

Desse modo, no primeiro mandato do Governo André Puccinelli (2007-2010), a Lei ${ }^{\circ}$ $3.479 / 2007$ alterou a forma de provimento do cargo de diretores escolares, de eleição com voto direto e secreto para seleção, seguida de eleição, na medida em que, somente após cumprir as duas primeiras etapas, os aprovados poderão participar da eleição.

Nesse período, em âmbito nacional, no segundo mandato do Governo Luiz Inácio Lula da Silva (2007-2010) foi lançado pelo Ministério da Educação (MEC) o Plano de Desenvolvimento da Educação (PDE), ao mesmo tempo em que o Decreto nº 6.094 de 24 de abril de 2007 instituiu o Plano de Metas Compromisso Todos pela Educação, dispositivo legal que colocou em vigência o PDE para a educação básica.

A adesão dos governos subnacionais ao "Compromisso", segundo o mesmo decreto, exigiu a elaboração do Plano de Ações Articuladas (PAR), para recebimento de assistência técnica e financeira do MEC com vistas à melhoria da qualidade da educação básica em sua esfera de competência, expressa pelo cumprimento de meta de evolução do índice de Desenvolvimento da Educação Básica (IDEB), observando-se as 28 diretrizes relacionadas no decreto (OLIVEIRA, 2014).

O PAR, portanto, tem caráter plurianual a ser elaborado conforme o documento "Instrumento de campo", a partir de diagnóstico local, estruturado em quatro dimensões: 
Gestão Educacional; Formação de Professores e dos Profissionais de Serviço e Apoio Escolar; Práticas Pedagógicas e Avaliação; Infraestrutura Física e Recursos Pedagógicos. Essas dimensões são compostas por áreas de atuação que, por sua vez, correspondem ao conjunto de características comuns usadas para agrupar os indicadores (BRASIL, 2008).

De acordo com Bartholomei (2013, p. 80), o governo de Mato Grosso do Sul aderiu ao Compromisso em 2007 e a equipe local elaborou o PAR, definindo ações e subações, com base nas dimensões indicadas, e encaminhou o documento ao MEC.

Por exemplo, na Dimensão 2 do PAR - "Formação de Professores e de Profissionais de Serviço e Apoio Escolar", foram definidas ações para a implementação das primeiras etapas do processo para provimento do cargo de diretores escolares, ou seja, "[...] a realização do Curso de Gestão Escolar e a avaliação de competências, para que o Estado de MS pudesse receber recursos federais" (BARTHOLOMEI, 2013, p. 105).

Constata-se que a Lei $\mathrm{n}^{\circ} 3.479$ de 2007 , ao instituir o processo denominado "eletivo", refere-se à "avaliação de competências básicas de dirigentes escolares". Porém, verifica-se no PAR elaborado no âmbito da Secretaria de Estado de Educação o termo "certificação", o que indica a introdução do mecanismo de certificação ocupacional, como parte do processo, que se caracteriza, de fato, como seletivo. Para tanto, foi contratada uma empresa privada, a Fundação Luís Eduardo Magalhães (FLEM), tendo em vista capacitar cerca de 1.500 professores, que após a aprovação no exame integrariam um Banco de Dados Único para, em seguida, participar de eleição na unidade escolar (BARTHOLOMEI, 2013, p. 96).

Assim, a exemplo do que ocorreu na Rede Municipal de Ensino de Campo Grande (2001-2004), o governo estadual de Mato Grosso do Sul, por intermédio da Secretaria de Estado de Educação, no dia 23 de abril de 2008, assinou um contrato com a Fundação Luís Eduardo Magalhães para oferecimento do "Curso de Gestão Escolar: Capacitação e Avaliação de Competências Básicas de Dirigentes Escolares e Candidatos ao Cargo" (BIGARELLA, 2015).

No que se refere aos recursos financeiros, Bartholomei (2013, p. 96), ao analisar o PAR da Rede Estadual de Ensino de Mato Grosso do Sul - 2007-2010 (MATO GROSSO DO SUL, 2008), mostra que, para financiar a ação "Curso de Capacitação de Coordenadores pedagógicos e professores da REE/MS", foi destinado o valor de $R \$ 460.605,00$, incluindo: deslocamento/participante ( $R$ \$ 80.00,00); hospedagem/alimentação/participante ( $R$ \$ 180.000,00); kit material participante $(R \$ 165.000,00)$; locação de espaço ( $R \$ 10.000,00)$; material de consumo $(\mathrm{R} \$ 25.605,00)$.

O documento especifica, para pagamento de "contratação de empresa especializada", na execução da subação 4, "Oferecer Certificação Ocupacional para os coordenadores pedagógicos e professores coordenadores da REE/MS", o valor anual de $\mathrm{R} \$ 500.000,00$, para transferência voluntária do MEC/FNDE para a SED/MS, em 2010 (BARTHOLOMEI, 2013, p. 102).

Em síntese, a autora mostra que, por meio de convênio entre a Secretaria de Estado de Educação de MS e o Ministério da Educação (MEC), foi definido o valor total de R\$ 986.165,00, para desenvolvimento de ações na Dimensão 2 - "Formação de Professores e de Profissionais de Serviço e Apoio Escolar", nomeadamente para o Indicador 2 - "Existência e implementação de políticas para a formação continuada das equipes pedagógicas que 
Relações entre o Setor Público e o Privado no Financiamento da Educação

atuam no Ensino Fundamental e Médio", entre outras, a formação de candidatos, tendo em vista a certificação ocupacional (BARTHOLOMEI, 2013, p. 104).

Desse modo, os dados acima apresentados evidenciam que o PAR propiciou a implementação de ações para realização do processo "eletivo" para provimento do cargo de diretores escolares na Rede Estadual de Ensino de Mato Grosso do Sul, com pagamento de recursos públicos a uma instituição privada.

Diante do exposto, considera-se que as ações educacionais instituídas nesse período pela Secretaria de Estado de Educação de Mato Grosso do Sul aproximam-se dos conteúdos gerenciais, destacando-se os mecanismos estabelecidos para forma de provimento do cargo de diretores escolares, com a contratação de uma empresa privada, além da introdução de premiação às escolas e estudantes com melhores resultados (OLIVEIRA; BIGARELLA, 2013).

Como analisam Oliveira e Bigarella (2013), evidencia-se a contradição entre a gestão democrática, definida como princípio do ensino pela Constituição Federal de 1988 e delegada pela LDBEN aos sistemas de ensino para regulamentação, e a gestão gerencial sustentada em critérios de produtividade, de eficiência e de qualidade dos sistemas educacionais e da escola, segundo a lógica da administração empresarial.

\section{Considerações Finais}

O que se apresentou neste artigo, com base na pesquisa documental, incluindo dados financeiros, foi a transferência de recursos públicos para uma instituição privada, ou seja, para a Fundação Luís Eduardo Magalhães, da Bahia, para execução da forma de provimento do cargo de diretores escolares, contratada em dois períodos e governos (municipal e estadual), ambos na gestão de André Puccinelli, do PMDB.

A contratação de uma empresa privada para desenvolvimento de ações no setor público de educação imprime, por meio de concepções e práticas expressas, entre outros, nos manuais utilizados nos cursos de gestão, a lógica privada na educação, com consequências para a gestão democrática da educação e da escola.

A configuração que a gestão escolar assume, tanto na Rede Municipal de Ensino de Campo Grande (MS), ao instituir o processo seletivo, incluindo o mecanismo da certificação ocupacional para provimento do cargo de diretores escolares, em 2002, no âmbito da parceria entre o governo do Município de Campo Grande (MS) com o Instituto Ayrton Senna, como na Rede Estadual de Ensino de Mato Grosso do Sul, ao alterar a dinâmica de acesso ao cargo de diretores escolares, de eleição direta para processo seletivo, incluindo, também, a certificação ocupacional, corresponde à perspectiva da gestão gerencial. Tal realidade distancia-se da perspectiva democrático-participativa, que prima pela gestão colegiada, pela autonomia (pedagógica, administrativa e financeira), pelo diálogo e decisão coletiva, entre outros pilares que materializam a gestão democrática.

\section{Referências}

ADRIÃO, Theresa. Educação e Produtividade: a reforma do ensino paulista e a desobrigação do Estado. São Paulo: Xamã, 2006. 
ADRIÃO, Theresa; BEZERRA, Egle Pessoa. O setor não lucrativo na gestão da educação pública: corresponsabilidade ou debilidade. Currículo sem Fronteiras, v. 13, n. 2, maio/ago., p. 256-268, 2013.

ADRIÃO, Theresa; GARCIA, Teise. Oferta educativa e responsabilização no PDE: O Plano de Ações Articuladas. Cadernos de Pesquisa, São Paulo, v. 38, n. 135, set./dez. 2008.

ADRIÃO, Theresa; GARCIA, Teise; BORGHI, Raquel; ARELARO, Lisete. Uma modalidade peculiar de privatização da educação pública: a aquisição de "sistemas de ensino" por municípios paulistas. Educação e Sociedade, Campinas, v. 30, n.108, p. 799-818, out. 2009.

BARTHOLOMEI, Maria Elisa Ennes. Provimento do cargo de diretores escolares, no âmbito do Plano de Ações Articuladas (PAR), na Rede Estadual de Ensino de Mato Grosso do Sul (2007-2010). 2013. 124 f. Dissertação (Mestrado em Educação) Universidade Católica Dom Bosco, Campo Grande, 2013.

BIGARELLA, Nadia. O papel do Conselho Estadual de Educação de Mato Grosso do Sul na definição de políticas de gestão para a educação básica (1999-2014). 2015. 252 f. Tese (Doutorado em Educação) - Universidade Católica Dom Bosco, Campo Grande, 2015.

BOLSON, Hildete da Silva Pereira. A certificação ocupacional de dirigentes escolares da rede municipal de ensino de Campo Grande - MS: implicações para a gestão escolar (2001-2004). 2011. Dissertação (Mestrado em Educação) - Universidade Católica Dom Bosco, Campo Grande, 2011.

BRASIL. Constituição da República Federativa do Brasil. Diário Oficial da União, Brasília, 5 out., 1988. Disponível em: <http://www.planalto.gov.br/ccivil_03/constituicao/ constituicaocompilado.htm>. Acesso em: 20 abr. 2012.

BRASIL. Plano Diretor da Reforma do Aparelho do Estado. Brasília: Ministério da Administração e Reforma do Estado, 1995.

BRASIL. Lei no 9.394, de 20 de dezembro de 1996. Estabelece as Diretrizes e Bases da Educação Nacional. Diário Oficial da União, Brasília, 1996. Disponível em: <www.planalto.gov.br/ccivil_03/leis/L9394.htm. Acesso em: 12 dez. 2013.

BRASIL. Emenda Constitucional no. 14, de 12 de setembro de 1996. Modifica os art. 34, 208, 211 e 212 da Constituição Federal e dá nova redação ao art. 60 do Ato de disposições constitucionais transitórias. Diário Oficial da União, Brasília, DF, 13 de set. 1996. Disponível em: http://www.planalto.gov.br/ccivil_03/constituicao/emendas/emc/emc14.htm. Acesso em 10 maio 2015.

BRASIL. Decreto Presidencial $n^{\circ}$ 6094, de 24 de abril 2007. Dispõe sobre a implementação do Plano de Metas Compromisso Todos pela Educação, pela União em regime de colaboração com municípios, Distrito Federal e Estados. Diário Oficial da União, Brasília, DF, 24 de abr. 2007. Disponível em: <http://www.planalto.gov.br/ccivil_03/_Ato20072010/2007/Decreto/D6094.htm>. Acesso em: 10 set. 2010.

BRASIL. Ministério da Educação. Instrumento de Campo. Brasília, 2008. Disponível em: <http://portal.mec.gov.br/arquivos/pdf/diagnostico.pdf>. Acesso em: 13 set. 2010. 
Relações entre o Setor Público e o Privado no Financiamento da Educação

CAMPO GRANDE. Lei Orgânica do Município de Campo Grande-MS. Diário Oficial de Campo Grande-MS, Câmara Municipal de Campo Grande, Campo Grande, 4 de abril de 1990.

CAMPO GRANDE. Termo de parceria que, entre si, celebram o município de Campo Grande - MS, com interveniência da Secretaria Municipal de Educação e o Instituto Ayrton Senna e a Fundação Banco do Brasil. Campo Grande, 24 de janeiro de 2001.

CAMPO GRANDE. Decreto n. 8.508, de 7 de agosto de 2002. Dispõe sobre o provimento de cargo de direção escolar e dá outras providências. Diário Oficial de Campo Grande-MS, Campo Grande, 8 ago. 2002a.

CAMPO GRANDE. Secretaria Municipal de Educação. Resolução SEMED n. 50, de 7 de agosto de 2002. Institui o processo seletivo para dirigentes das escolas municipais e dá outras providências. Diário Oficial de Campo Grande-MS, n. 1125, 2002b.

CAMPO GRANDE. Primeiro termo aditivo celebrado em 2 de setembro de 2002 ao termo de parceria celebrado em 24/01/2001. Campo Grande, 2 de set. 2002c.

CAMPO GRANDE. Segundo termo aditivo celebrado em $1^{\circ}$ de janeiro de 2003 , ao termo de parceria celebrado em 24/01/2001, Campo Grande, $1^{\circ}$ de janeiro de 2003a.

CAMPO GRANDE. Contrato n. 99, de prestação de serviço, que entre si celebram a Prefeitura Municipal de Campo Grande-MS e a Fundação Luis Eduardo Magalhães- Centro de Modernização da Administração e Desenvolvimento da Administração Pública. Campo Grande, 22 de julho de 2003b.

CAMPO GRANDE. Terceiro termo aditivo celebrado em $1^{\circ}$ de janeiro de 2004 , ao termo de parceria celebrado em 24/01/2001. Campo Grande, $1^{\circ}$ de janeiro de 2004a.

CAMPO GRANDE. Prefeitura Municipal. Rede Municipal de Ensino: política educacional. Campo Grande: Secretaria Municipal de Educação, 2004b.

DANTAS, Luciana Cristina Lopes. Política de gestão escolar da rede municipal de ensino de Campo Grande, MS: implicações da parceria público-privada (2005-2008). 2011. Dissertação (Mestrado em Educação) - Universidade Católica Dom Bosco, Campo Grande, 2011.

DOURADO, Luiz F. A escolha de dirigentes escolares: política e gestão da educação no Brasil. In: FERREIRA, Naura Syria Carapeto (Org.). Gestão Democrática Da Educação: atuais tendências, novos desafios. São Paulo: Cortez, 2001.

FERNANDES, Maria Dilneia. Recentes regulações na gestão da educação básica brasileira: entre o Estado e o mercado. In: CONGRESSO IBERO LUSO BRASILEIRO, 1., 2010, Cacéres e Mérida. Anais... Cacéres e Mérida, 2010. Disponível em: <http://www.anpae.org.br/iberolusobrasileiro2010/cdrom/76.pdf>. Acesso em: 4. Jan. 2013.

FUNDAÇÃO LUÍS EDUARDO MAGALHÃES. Agência de Certificação Ocupacional. Proposta Técnica. Salvador, 26 de abril de 2004.

MATO GROSSO DO SUL. Lei $n^{\circ} 3.244$, de 6 de julho de 2006. Dispõe sobre a eleição de diretores, diretores-adjuntos e do colegiado escolar da rede estadual de ensino de Mato Grosso do Sul e dá outras providências. Diário Oficial do Estado de Mato Grosso do Sul, Campo Grande, 2006. 
Relações entre o Setor Público e o Privado no Financiamento da Educação

MATO GROSSO DO SUL. Lei $n^{\circ} 3.479$, de 20 de dezembro de 2007 . Dispõe sobre o processo eletivo de dirigentes escolares da rede estadual de ensino, dá nova redação a dispositivo da Lei $n^{\circ} 3.244$, de 6 de junho de 2006, e dá outras providências. Diário Oficial do Estado de Mato Grosso do Sul, Campo Grande, MS, 2007.

MATO GROSSO DO SUL. Plano de Ações Articuladas de Mato Grosso do Sul - 20072010. Campo Grande, 2008.

MATO GROSSO DO SUL. Mensagem à Assembleia Legislativa, de 6 de fevereiro de 2009: governador André Puccinelli. Campo Grande, MS, 2009.

OLIVEIRA, Regina Tereza Cestari. A relação público/privado e o direito à educação. In: CARVALHO, Carlos Henrique (Org.) Desafios da produção e da divulgação do conhecimento. Uberlândia: EDUFU, 2012.

OLIVEIRA, Regina Tereza Cestari (Coord.) Parcerias público e privado na educação: implicações para a oferta e gestão educacional. Relatório final de pesquisa. Campo Grande: FUNDECT, 2013.

OLIVEIRA, Regina Tereza Cestari. O Plano de Ações Articuladas (PAR) e a qualidade da educação básica. In: SILVA, Maria Abádia; CUNHA, Célio (Org.). Educação Básica: políticas avanços e pendências. Campinas: Autores Associados, 2014. p. 151-177.

OLIVEIRA, Regina Tereza Cestari; BIGARELLA, Nadia. Políticas de gestão da Educação Básica no Estado de Mato Grosso do Sul: programas e concepções (1991-2000). In: SCAFF, Elisangela; LIMA, Paula Gomes; ARANDA, Maria A. (Org.). Política e gestão da educação básica: desafios à alfabetização. São Paulo: Expressão \& Arte, 2013.

PERONI, Vera. A relação público/privado e a gestão da educação em tempos de redefinição do papel do Estado. In: ADRIÃO, Theresa; PERONI, Vera. Público e Privado na Educação. São Paulo: Xamã, 2008.

PERONI, Vera Maria Vidal; OLIVEIRA, Regina Tereza Cestari; FERNANDES, Maria Dilneia Espindola. Estado e terceiro setor: as novas regulações entre o público e o privado na gestão da educação básica brasileira. Educação e Sociedade, Campinas, v. 30, n. 108, p. 761-778, out. 2009.

Regina Tereza Cestari de Oliveira é Doutora em Educação pela Universidade Estadual de Campinas (Unicamp). Professora do Programa de Pós-Graduação em Educação - Mestrado e Doutorado da Universidade Católica Dom Bosco. Pesquisadora produtividade em pesquisa CNPq.

E-mail: reginacestari@hotmail.com 


\title{
Editores do volume 8
}

José Marcelino de Rezende Pinto - Universidade de São Paulo, São Paulo/SP, Brasil

Nalú Farenzena - Universidade Federal do Rio Grande do Sul, Porto Alegre/RS, Brasil

\section{Comitê Editorial}

José Marcelino de Rezende Pinto - Universidade de São Paulo, Brasil

Juca Gil - Universidade Federal do Rio Grande do Sul, Brasil

Theresa Adrião - Universidade Estadual de Campinas, Brasil Ângelo

Ricardo de Souza - Universidade Federal do Paraná, Brasil

Márcia Aparecida Jacomini - Universidade Federal de São Paulo, Brasil

\section{Conselho Editorial}

\section{Alejandro Morduchowicz}

Universidad Pedagógica, Provincia de Buenos Aires, Argentina

Fernanda Saforcada

Universidade de Buenos Aires, Argentina

Jacques Velloso

Universidade de Brasília, Brasil

João Monlevade

Senado Federal, Brasil

Jorge Abrahão de Castro

Instituto de Pesquisa Econômica Aplicada / IPEA, Brasil

Juca Gil

Universidade Federal do Rio Grande do Sul, Brasil

Lisete Regina Gomes Arelaro

Universidade de São Paulo, Brasil

Luis Carlos Sales

Universidade Federal do Piauí, Brasil

Luiz de Sousa Junior

Universidade Federal da Paraíba, Brasil

Luiz Fernandes Dourado

Universidade Federal de Goiás, Brasil

Magna França

Universidade Federal do Rio Grande do Norte, Brasil

\section{Maria Beatriz Luce}

Universidade Federal do Pampa, Brasil

Universidade Federal do Rio Grande do Sul, Brasil

Marcos Edgar Bassi

Universidade Federal do Paraná, Brasil

\author{
Maria Dilnéia Espíndola Fernandes \\ Universidade Federal de Mato Grosso do Sul, Brasil \\ Nalú Farenzena \\ Universidade Federal do Rio Grande do Sul, Brasil \\ Nelson Cardoso do Amaral \\ Universidade Federal de Goiás, Brasil \\ Nicholas Davies \\ Universidade Federal Fluminense, Brasil \\ Rosana Evangelista Cruz \\ Universidade Federal do Piauí, Brasil \\ Rosana Gemaque \\ Universidade Federal do Pará, Brasil \\ Robert E. Verhine \\ Universidade Federal da Bahia, Brasil \\ Romualdo Portela de Oliveira \\ Universidade de São Paulo, Brasil \\ Theresa Adrião \\ Universidade Estadual de Campinas, Brasil \\ Tristan McCowan \\ University of London, Reino Unido \\ Vera Jacob \\ Universidade Federal do Pará, Brasil \\ Vera Peroni \\ Universidade Federal do Rio Grande do Sul, Brasil \\ Vitor Henrique Paro \\ Universidade de São Paulo, Brasil
}

\section{Equipe editorial}

Apoio ao Comitê Editorial: Patrícia Balthazar Garcia

Diagramação, Revisão de português e normalização: Edson Leonel de Oliveira

Revisão de inglês: Ananyr Porto Fajardo 